\title{
PENGARUH MOTIVASI BELAJAR TERHADAP KEMAMPUAN MENULIS PANTUN BAHASA DAERAH
}

\author{
Hidayatun Nur \\ Universitas Islam Riau, Pekanbaru, Indonesia \\ hidayatunnur@edu.uir.ac.id
}

\begin{abstract}
Writing ability is one of the language skills possessed by a person. One of the skills to write old poetry is pantun. Pantun develops in the people of the archipelago with a variety of regional languages. This study aimed to determine the effect of learning motivation on the ability to write local language rhymes. This study uses multiple linear regression analysis. From the research results, it can be seen that the learning motivation is in a good category and the ability to write local language pantun is in a good category. The motivation of learning showed an influence on the poetry writer's ability, which was proven that the significance value was 0.000 that smaller than the probability of 0.05 . From the research results, it can be seen that the learning motivation contributed $49.4 \%$ to the ability to write regional language pantun, and other factors influenced the remaining 50.6\%.
\end{abstract}

Keyword: motivation to learn, writing rhymes, local languages

\begin{abstract}
ABSTRAK
Kemampuan menulis merupakan salah satu kemampuan bahasa yang dimiliki oleh seseorang. Salah satu kemampuan menulis puisi lama adalah pantun. Pantun berkembang pada masyarakat nusantara dengan berbagai macam bahasa daerah. Tujuan penelitian ini untuk mengetahui pengaruh motivasi belajar terhadap kemampuan menulis pantun bahasa daerah. Penelitian ini menggunakan analisis regresi linear berganda. Dari hasil penelitian dapat diketahui bahwa motivasi belajar termasuk dalam kategori baik dan kemampuan menulis pantun bahasa daerah termasuk dalam kategori baik. Motivasi belajar menunjukan pengaruh kepada kemampuan penulis pantun yang dibuktikan bahwa signifikansi memiliki nilai 0.000 lebih kecil dari probabilitas 0.05 . Dari hasil penelitian dapat diketahui bahwa motivasi belajar memberikan kontribusi $49.4 \%$ terhadap kemampuan menulis pantun bahasa daerah dan sisanya $50.6 \%$ dipengaruhi oleh faktor lain.
\end{abstract}

Keyword: motivasi belajar, menulis pantun, bahasa daerah

\section{PENDAHULUAN}

Kemampuan menulis merupakan sebuah keterampilan bahasa yang dimiliki oleh seseorang. Selain menulis kemampuan berbahasa yang lain adalah membaca, berbicara, dan menyimak. Kemampuan menulis penting untuk dimiliki oleh seseorang untuk menunjukkan kemampuan berbahasanya berkembang dengan baik. Dalam kehidupan sehari-hari kemampuan menulis membantu seseorang untuk menunjukkan ide-ide atau gagasannya untuk disampaikan kepada orang lain. Ide-ide atau gagasan tersebut lebih mudah sampai kepada orang lain tanpa harus orang tersebut bertemu langsung dengan orang yang membaca tulisannya.

Menulis memiliki tujuan diantaranya mengekspresikan diri, memberikan informasi 
kepada pembaca, mempersuasi pembaca, dan untuk menghasilkan tulisan. Menulis memiliki tujuan yang banyak diantaranya menulis dapat menjadi jempatan seseorang untuk menyampaikan informasi, mengekpresikan diri, menyampaikan ide-ide maupun gagasan kepada orang lain. Tulisan yang disampaikan dalam bentuk yang menarik a memberikan daya pikat yang tinggi bagi pembacanya. Jika hal ini terjadi tujuan dari penulisan tersebut dapat dicapai dengan baik. Selain menulis tersebut memiliki tujuan menulis juga memberikan dampak yang baik baik penulis. Diantara dampak tersebut adalah penulis melatih daya ingat kreativitas yang ada di dalam dirinya. Penulis juga akan menampah pengetahuannya karena dengan menulis, penulis akan selalu mencari informasi yang relevan dan terbaru sehingga hasil tulisannya akan lebih baik lagi. Menulis merupakan bentuk dari keberanian dari seorang penulis, karena dari tulisan yang dibuatnya penulis dapat menyampaikan ide-ide atau gagasan yang dapat dipahami oleh orang lain.

Tulisan dapat disampaikan dalam bentuk tulisan bisa atau dalam bentuk tulisan sastra atau puisi. Salah satu bentuk puisi adalah pantun.. Jika dilihat dari defenisi (Maulina, 2012) menjelaskan pantun merupakan salah satu bentuk dari puisi lama yang berkembang luas dimasyarakat nusantara. Pantun merupakan salah satu bentuk dari sastra lisan. Pantun biasanya memiliki empat lirik atau empat baris bila dituliskan. Setiap baris terdiri dari 8-12 suku kata dengan bersajak akhir berpolakan $a-b-a-b$ dan $a-a-a-a$. bentuk pantun terdiri dari sampiran dan isi. Sampiran merupakan dua baris pertama dan dua baris terkahir merupakan isi. Menulis pantun memerlukan daya imajinasi yang baik sehingga penulis mendapatkan kata-kata yang baik dan indah yang kemudian dituliskan sehingga serbentuk sebuah pantun yang mengandung makna yang mendalam. Kemampuan menulis memerlukan latihan yang terus menerus sehingga kemampuan menulis pantun terlatih.

Pantun merupakan salah satu bentuk tata bicara yang mengatur seseorang untuk menyampaikan maksud dengan lebih baik dan halus sehingga sasaran pendengarnya dapat memahami tujuan pantun dan tidak merasa tersinggung. Pantun melatih seseorang untuk berujar dengan bijak, berpikir dahulu sebelum berkata. Pantun melatih penuturnya untuk berpikir asosiatif untuk menggabungkan beberapa kata sehingga tercipta kalimat-kalimat yang baik dan indah. Untuk pantun perlu dibudayakan terutama kepada anak-anak muda atau siswa yang ada disekolah.

Hasil penelitian dari (Afrilia, Hamizi, \& Witri, 2015) menyebutkan bahwa Kemampuan siswa dalam menulis pantun masih termasuk dalam kategori rendah. Kondisi ini terlihat dari kemampuan menulis pantun dari aspek segi jumlah baris, jumlah suku kata, persajakan dan isi. Berangkat dari hasil penelitian ini perlu untuk digali informasi kemampuan siswa dan dilihat dari aspek motivasi belajar siswa.

Dari hasil pengamatan awal dapat diketahui bahwa siswa belum mampu dan masih takut menuliskan ide menjadi sebuah pantun. Dari kondisi tersebut penulis tertarik untuk melakukan penelitian tentang pengaruh motivasi belajar terhadap kemampuan menulis pantun Bahasa Daerah.

Rumusan masalah dari penelitian ini adalah:

a. Bagaimana motivasi belajar siswa kelas V di SDN 005 Bukit Ranah Kecamatan Kampar Kabupaten Kampar

b. Bagaimana kemampuan menulis pantun Bahasa daerah siswa kelas V di SDN 005 Bukit Ranah Kecamatan Kampar Kabupaten Kampar

c. Berapa besar pengaruh motivasi belajar terhadap kemampuan menulis pantun Bahasa daerah siswa kelas V di SDN 005 Bukit Ranah Kecamatan Kampar Kabupaten Kampar

Adapun tujuan dari penelitian ini adalah untuk

a. Megetahui motivasi belajar siswa kelas V di SDN 005 Bukit Ranah Kecamatan Kampar Kabupaten Kampar

b. Megetahui kemampuan menulis pantung Bahasa daerah siswa kelas V di SDN 005 Bukit Ranah Kecamatan Kampar Kabupaten Kampar 
c. Megetahui pengaruh motivasi belajar terhadap kemampuan menulis pantun Bahasa daerah siswa kelas V di SDN 005 Bukit Ranah Kecamatan Kampar Kabupaten Kampar

Manfaat dari penelitian ini adalah untuk

a. Bagi instansi

Penelitian ini dapat memberikan informasi tentang motivasi anak dan kemampuan menulis pantun Bahasa daerah yang dapat dijadikan sebagai masukan untuk meningkatkan kegiatan proses belajar mengajar

b. Bagi penulis

Penelitian ini dapat memberikan informasi yang dapat digunakan untuk dasar penulis mengembangkan pembelajaran dan bahan ajar untuk pengembangan keilmuan.

\section{METODOLOGI PENELITIAN}

Penelitian dilaksanakan di SDN 005 Bukit Ranah Kecamatan Kampar. Sampel penelitian siswa kelas V sebanyak 30 orang. Metode penelitian menggunakan analisis regresi linear berganda yang melihat pengaruh dari variabel $\mathrm{X}$ terhadap Variabel $\mathrm{Y}$. Variabel $\mathrm{X}$ atau variabel independen adalah Motivasi Belajar dan Variabel Y atau variabel dependent adalah kemampuan menulis pantun. Untuk kriteria penilaian peneitian adalah berikut ini:

Tabel 1. Kriteria Penilaian

\begin{tabular}{cccl}
\hline \multicolumn{3}{c}{ Kriteria Penilaian } \\
\hline 0 & - & 20 & Sangat Kurang \\
\hline 21 & - & 40 & Kurang \\
\hline 41 & - & 60 & Cukup \\
\hline 61 & - & 80 & Baik \\
\hline 81 & - & 100 & Sangat Baik \\
\hline
\end{tabular}

\section{HASIL DAN PEMBAHASAN}

Dari hasil penelitian didapatkan data berikut ini:

Tabel 2. Deskriptif Motivasi Belajar

\begin{tabular}{clccc}
\hline No & Indikator & $\begin{array}{c}\text { Nilai } \\
\text { Aktual }\end{array}$ & $\%$ & Ket. \\
\hline 1 & $\begin{array}{l}\text { Kuatnya } \\
\text { kemauan }\end{array}$ & 71 & $79 \%$ & Baik \\
\hline
\end{tabular}

\begin{tabular}{|c|c|c|c|c|}
\hline & $\begin{array}{l}\text { untuk } \\
\text { membuat } \\
\text { pantun } \\
\text { berbahasa } \\
\text { daerah }\end{array}$ & & & \\
\hline 2 & $\begin{array}{l}\text { Ketekunan } \\
\text { dalam } \\
\text { mengerjakan } \\
\text { membuat } \\
\text { pantun } \\
\text { berbahasa } \\
\text { daerah }\end{array}$ & 61 & $68 \%$ & Baik \\
\hline 3 & $\begin{array}{l}\text { Jumlah waktu } \\
\text { yang } \\
\text { disediakan } \\
\text { dalam } \\
\text { membuat } \\
\text { pantun } \\
\text { berbahasa } \\
\text { daerah } \\
\end{array}$ & 69 & $77 \%$ & Baik \\
\hline 4 & $\begin{array}{l}\text { Ulet } \\
\text { menghadapi } \\
\text { kesulitan } \\
\text { (tidak lekas } \\
\text { puas) } \\
\text { membuat } \\
\text { pantun } \\
\text { berbahasa } \\
\text { daerah }\end{array}$ & 62 & $69 \%$ & Baik \\
\hline 5 & $\begin{array}{l}\text { Kerelaan } \\
\text { meninggalkan } \\
\text { kewajiban atau } \\
\text { tugas lain } \\
\text { membuat } \\
\text { pantun } \\
\text { berbahasa } \\
\text { daerah } \\
\end{array}$ & 63 & $70 \%$ & Baik \\
\hline 6 & $\begin{array}{l}\text { Adanya } \\
\text { harapan dalam } \\
\text { membuat } \\
\text { pantun } \\
\text { berbahasa } \\
\text { daerah }\end{array}$ & 66 & $73 \%$ & Baik \\
\hline 7 & $\begin{array}{l}\text { Lebih senang } \\
\text { bekerja sendiri } \\
\text { membuat } \\
\text { pantun } \\
\text { berbahasa }\end{array}$ & 54 & $60 \%$ & $\begin{array}{c}\text { Cuku } \\
\text { p }\end{array}$ \\
\hline
\end{tabular}




\begin{tabular}{cccc}
\hline daerah & & & \\
\hline Jumlah & $\mathbf{6 3 . 7 1}$ & $\mathbf{7 1 \%}$ & Baik \\
\hline
\end{tabular}

Dari hasil penelitian dapat diketahui bahwa secara keseluruhan motivasi belajar siswa termasuk dalam katogori baik hal ini dapat dilihat dari nilai yang diperoleh sebanyak $70 \%$ yang termasuk dalam kategori baik. (Emda, 2017) motivasi memiliki peran penting dalam pembelajaran. Motivasi berupa motivasi intrinsik dan motivasi ekstrinsi. Motivasi tidak hanya muncul dari siswa tetapi juga dari guru yang memberikan motivasi kepada peserta didik. Motivasi akan mengubah semangat belajar siswa. Memberikan motivasi dapat memberikan keyakinan kepada siswa sehingga siswa memiliki keinginan untuk belajar. (I. S. Angraini, 2011) terdapat dua faktor yang memotivasi seseorang untuk belajar. 1) motivasi yang muncul dari dalam diri atau internal. Motivasi ini muncul karena keadaran diri pentingnya kegunaan belajar untuk mengembangkan diri untuk masa depan. 2) motivasi yang muncul dari luar. Motivasi ini dapat berupa rangsangan yang diberikan oleh orang lain yang dapat memberikan pengaruh kepada psikologis seseorang. (Daud, 2012) motivasi belajar yang tinggi sejalan dengan hasil belajar yang tinggi. Motivasi belajar memberikan dampak kepada hasil belajar siswa. (Ulfah, Santoso, \& Utaya, 2016) motivasi belajar akan mempengaruhi hasil belajar siswa sebaliknya jika motivasi rendah maka hasil belajar juga akan rendah. Diantara bentuk dari motivasi tersebut dapat berupa citacita, kemampuan siswa, kondisi siswa kesehatan jasmani dan rohani.

(Oktiani, 2017) belajar merupakan aktivitas yang dilakukan dengan sengaja dan sadar untuk mendapatkan konsep, pengetahuan, dan pemahaman untuk merubah perilaku yang dimiliki oleh seseorang. Untuk mencapai tujuan belajar tersebut diperlukan motivasi. Motivasi belajar dapat diartikan siswa menggunakan semua daya yang ada pada diri siswa pada kegiatan pembelajaran dari awal sampai akhir belajar tersebut. Selain dari diri siswa peran guru untuk menstimulasi motivasi sangat diperlukan agar motivasi siswa dapat meningkat untuk belajar. (Marisa, 2019) belajar merupakan proses perubahan pada diri seseorang dari tidak tahu menjadi tahu. Belajar merupakan proses yang penting dilalui oleh setiap individu. Untuk belaja tersebut diperlukan dorongan berupa motivasi dalam belajar. Dalam proses belajar yang menjadi permasalahan adalah ranah kognitif, afektif, dan psikomotor.

(V. D. Angraini, Mukhadis, \& Muladi, 2013) pemberian modifikasi pembelajaran meningkatkan motivasi belajar siswa dibandingkan dengan cara yang konvensional. Memberikan sarana belajar seperti modul juga dapat memberikan semangat belajar siswa sehingga berdampak pada motivasi belajar siswa itu sendiri. (Afandi, 2015) memberikan media pembelajaran memberikan peningkatan pada motivasi belajar siswa. Kebosahan belajar yang terjadi pada anak dapat dihilangkan dengan cara memberikan modifikasi pembelajaran salah satunya dengan memberikan media pembelajaran yang menarik kepada anak.

Tabel 3. Deskriptif Kemampuan Menulis Pantun Bahasa Daerah

\begin{tabular}{llccc}
\hline No & Indikator & $\begin{array}{c}\text { Nilai } \\
\text { Aktual }\end{array}$ & $\%$ & Ket. \\
\hline 1 & $\begin{array}{l}\text { Kesesuaian } \\
\text { dengan } \\
\text { kriteria } \\
\text { pantun }\end{array}$ & 73 & $81 \%$ & Baik \\
\hline 2 & $\begin{array}{l}\text { Kemenarikan } \\
\text { isi pantun }\end{array}$ & 78 & $87 \%$ & Baik \\
\hline 3 & $\begin{array}{l}\text { Kekuatan } \\
\text { imajinasi }\end{array}$ & 79 & $88 \%$ & Baik \\
\hline 4 & $\begin{array}{l}\text { Ketepatan } \\
\text { diksi dan } \\
\text { ejaan }\end{array}$ & 72 & $80 \%$ & Baik \\
\hline 5 & Persajakan & 81 & $90 \%$ & Baik \\
\hline & Jumlah & 76.60 & $85 \%$ & Baik \\
\hline
\end{tabular}

(Murti, 2017) karakteristik pantun terletak pada terjalinnya sampiran dan isi yang memiliki tema tersendiri yang membangun suatu keutuhan makna yang begitu luas. Pantun sudah berkembang dari dahulu sampai saat sekarang ini. Pantun telah menyebar dan digunakan diberbagai daerah. (Wulansari, 2016) pantun 
dapat dikatakan sebagai ciri khas orang melayu, dalam pantun seseorang dapat mengungkapakan isi hati, pengalaman, dan sosial budaya dengan cara yang sopan dan halus dalam situasi apapun baik formal ataupun non formal. Pantun dapat membuat orang berpikir logis tetapi tetap artistik dengan pilihan diksi yang tepat yang pernuh harmoni sehingga pembaca dan pendengar dapat menikmati dan memahami arti yang disampaikan.

(Pratiwi, Hidayat, \& Fauzi, 2020) menulis teks pantun pada siswa terdapat beberapa kekeliruan diantaranya 1) kekeliruan memahami diksi, 2) kekeliruan terhadap struktur teks (rima), dan 3) kekurangan imajinasi. Penyebab terjadi kekeliruan yaitu kurangnnya pemahaman siswa pada kaidah pembuatan struktur pantun sehingga mengakibatkan penempatan kosa kata yang tidak sesuai dengan pantun. (Multafifin, 2015) nilai siswa mampu menulis pantun yang tinggi ada pada aspek larik dibandingkan dengan aspek-aspek yang lain.

(Hidayani \& Arif, 2017) kemampuan menulis pantun siswa perlu ditingkatkan lagi. Siswa perlu lebih banyak membaca dan juga menulis untuk menambah wawasan dan pengetahuan. Untuk menulis pantun siswa perlu diberikan bimbingan. Guru sebagai pengajar perlu melatih siswa dengan cara bersama-sama dengan siswa untuk membuat pantun dengan memperhatikan syarat-syarat pantun dan memancing keingintahuan siswa terhadap pantun. (Indrayeni, Hakim, \& Burhanudin, 2019) permasalahan penulisan pantun pada siswa sampiran yang ditulis dominan ditulis dengan tulisan yang kurang puitis, tidak mengandung pesan dan tidak memiliki hubungan dengan isi pantun. Pada aspek isi siswa sudah mampu menulis dengan kata kata yang jelas, transparan dan lugas sehingga tidak diperlukan untuk penafsiran. Dalam aspek rima siswa masih memiliki perbedaan yang banyak. Kemampuan menulis pantun anak dipengaruhi oleh lingkungan belajar, motivasi, jam belajar dan lingkungan kelas. (Irnawati, Kurniati, \& Wibowo, 2017) siswa yang sudah terbiasa menulis pantun memiliki kemapuan untuk berbalas pantun. Pengaruh Motivasi Belajar Terhadap Kemampuan Menulis Pantun Bahasa Daerah dapat dilihat dari hasil statistik berikut ini:

\begin{tabular}{|c|c|c|c|c|}
\hline \multicolumn{5}{|c|}{ Tabel 4. Model Summary ${ }^{\mathrm{b}}$} \\
\hline \multirow[b]{3}{*}{ Model } & \multirow[b]{3}{*}{$\mathrm{R}$} & \multirow{3}{*}{$\begin{array}{c}\mathrm{R} \\
\text { Square }\end{array}$} & ted $\mathrm{R}$ & Std. Error \\
\hline & & & \multirow[t]{2}{*}{ Square } & of the \\
\hline & & & & Estimate \\
\hline 1 & $.703^{\mathrm{a}}$ & .494 & .476 & 1.83110 \\
\hline $\begin{array}{l}\text { a. Predi } \\
\text { b. Depe }\end{array}$ & 118 & $\begin{array}{l}\text { stant), } \mathrm{K} \\
\text { ble: } \mathrm{Mo}\end{array}$ & $\begin{array}{l}\text { puan M } \\
\text { Belajar }\end{array}$ & als Pantun \\
\hline
\end{tabular}

\begin{tabular}{|c|c|c|c|c|c|}
\hline \multicolumn{6}{|c|}{ Tabel 5. Anova ${ }^{a}$} \\
\hline Model & $\begin{array}{l}\text { Sum of } \\
\text { Squares }\end{array}$ & Df & $\begin{array}{l}\text { Mean } \\
\text { Squar } \\
\text { e }\end{array}$ & F & Sig. \\
\hline 1 Regression & 91.585 & 1 & $\begin{array}{r}91.58 \\
5\end{array}$ & 27.315 & $.000^{\mathrm{b}}$ \\
\hline Residual & 93.882 & 28 & 3.353 & & \\
\hline Total & 185.467 & 29 & & & \\
\hline $\begin{array}{l}\text { a. Dependent } \\
\text { b. Predictors: }\end{array}$ & $\begin{array}{l}\text { ariable: } \mathrm{M} \\
\text { Constant), }\end{array}$ & $\begin{array}{l}\text { otiva } \\
\text { Kem }\end{array}$ & $\begin{array}{l}\text { i Belaj } \\
\text { mpuan }\end{array}$ & Menuls & ntun \\
\hline
\end{tabular}

Tabel 6. Coefficients ${ }^{\mathrm{a}}$

Unstandardized Standardized

\begin{tabular}{|c|c|c|c|c|c|}
\hline \multirow[b]{2}{*}{ Model } & \multicolumn{2}{|c|}{$\begin{array}{l}\text { Unstandardized } \\
\text { Coefficients }\end{array}$} & $\begin{array}{l}\text { Standardized } \\
\text { Coefficients }\end{array}$ & \multirow[b]{2}{*}{$\mathrm{T}$} & \multirow[b]{2}{*}{ Sig. } \\
\hline & B & $\begin{array}{l}\text { Std. } \\
\text { Error }\end{array}$ & Beta & & \\
\hline $\begin{array}{ll}1 & \text { (Constan } \\
\text { t) }\end{array}$ & 7.422 & 1.463 & & 5.073 & .000 \\
\hline $\begin{array}{l}\text { Kemamp } \\
\text { uan } \\
\text { Menuls } \\
\text { Pantun }\end{array}$ & .583 & .112 & .703 & 5.226 & .000 \\
\hline
\end{tabular}

Tabel 7. Residuals Statistics ${ }^{\mathrm{a}}$

\begin{tabular}{|c|c|c|c|c|c|}
\hline & Minimu & $\mathrm{Ma}$ & & $\begin{array}{c}\text { Std. } \\
\text { Deviatio }\end{array}$ & \\
\hline & $\mathrm{m}$ & $\mathrm{m}$ & Mean & & $\mathrm{N}$ \\
\hline $\begin{array}{l}\text { Predicte } \\
\text { d Value }\end{array}$ & 10.3380 & 16.1689 & $\begin{array}{r}14.866 \\
7 \\
\end{array}$ & 1.77711 & $\begin{array}{l}3 \\
0 \\
\end{array}$ \\
\hline $\begin{array}{l}\text { Std. } \\
\text { Predicte } \\
\text { d Value }\end{array}$ & -2.548 & .733 & .000 & 1.000 & $\begin{array}{l}3 \\
0 \\
0\end{array}$ \\
\hline $\begin{array}{l}\text { Standard } \\
\text { Error of } \\
\text { Predicte } \\
\text { d Value }\end{array}$ & .335 & .929 & .441 & .174 & $\begin{array}{l}3 \\
0\end{array}$ \\
\hline $\begin{array}{l}\text { Adjusted } \\
\text { Predicte } \\
\text { d Value }\end{array}$ & 9.7622 & 16.2875 & $\begin{array}{r}14.877 \\
9 \\
\end{array}$ & 1.77620 & 3 \\
\hline Residual & -3.41963 & 2.99728 & .00000 & 1.79925 & 0 \\
\hline
\end{tabular}




\begin{tabular}{|c|c|c|c|c|c|}
\hline $\begin{array}{l}\text { Std. } \\
\text { Residual }\end{array}$ & -1.868 & 1.637 & .000 & .983 & $\begin{array}{l}3 \\
0 \\
\end{array}$ \\
\hline $\begin{array}{l}\text { Stud. } \\
\text { Residual }\end{array}$ & -1.902 & 1.665 & -.003 & 1.012 & $\begin{array}{l}3 \\
0 \\
\end{array}$ \\
\hline $\begin{array}{l}\text { Deleted } \\
\text { Residual } \\
\end{array}$ & -3.54555 & 3.10128 & -.01119 & 1.91348 & $\begin{array}{l}3 \\
0 \\
\end{array}$ \\
\hline $\begin{array}{l}\text { Stud. } \\
\text { Deleted } \\
\text { Residual } \\
\end{array}$ & -2.001 & 1.723 & -.002 & 1.031 & $\begin{array}{l}3 \\
0\end{array}$ \\
\hline $\begin{array}{l}\text { Mahal. } \\
\text { Distance }\end{array}$ & .006 & 6.494 & .967 & 1.925 & $\begin{array}{l}3 \\
0 \\
\end{array}$ \\
\hline $\begin{array}{l}\text { Cook's } \\
\text { Distance }\end{array}$ & .000 & .192 & .033 & .042 & $\begin{array}{l}3 \\
0 \\
\end{array}$ \\
\hline $\begin{array}{l}\text { Centered } \\
\text { Leverage } \\
\text { Value } \\
\end{array}$ & .000 & .224 & .033 & .066 & $\begin{array}{l}3 \\
0\end{array}$ \\
\hline
\end{tabular}

Secara umum rumus persamaan regresi linar sederhana adalah $\mathrm{Y}=\mathrm{a}+\mathrm{bx}$. Untuk megetahui nilai koefisien tersebut dapat digunakan pedoman dari kolan koefisien yang menghasilkan data:

$\mathrm{a}=$ angka dari unstandized Coefisients, dalam perhitungan ini didapatkan nilainya sebesar 7.422 yang merupakan angka konstan yang memiliki makna tidak ada motivasi belajar (X) maka nilai kemampuan menulis pantun (Y) sebesar 7.422

$\mathrm{b}=$ angka koefisien regresi, nilai yang didapatkan dari perhitungan ini yaitu 0.583. angka ini memiliki makna bahwa setiap peningkatan $1 \%$ motivasi belajar (X) akan meningkatkan kemampuan menulis pantun $(\mathrm{Y})$ sebesar 0.583. Adapun menjadi dasar pengambilan keputusan dalam analisis regresi dengan melihat nilai sifnifikansi (Sig.) hasil output SPSS adalah:

1. Jika nilai signifikansi (Sig.) lebih kecil < dari probabilitas 0.05 mengandung arti bahwa ada pengaruh motivasi belajar terhadap kemampuan menulis pantun bahasa daerah siswa kelas V di SDN 005 bukit Ranah Kecamatan Kampar.

2. Sebaliknya, Jika nilai signifikansi (Sig.) lebih besar > dari probabilitas 0.05 mengandung arti bahwa tidak ada pengaruh motivasi belajar terhadap kemampuan menulis pantun bahasa daerah siswa kelas V di SDN 005 bukit Ranah Kecamatan Kampar.

Dari hasil penelitian dapat diketahui bahwa nilai sifnifikansi (Sig.) sebesar 0.000 lebih kecil < dari porbalitas 0.05, dapat diasumsikan bahwa $\mathrm{HO}$ ditolah dan Ha diterima artinya terdapat pengaruh motivasi belajar terhadap kemampuan menulis pantun bahasa daerah siswa kelas V di SDN 005 bukit Ranah kecamatan Kampar. Dari hasil perhitungan R Square didapat nilai perhitungan sebesar 0.494. angka ini memiliki arti bahwa pengaruh motivasi belajar terhadap kemampuan menulis pantun bahasa daereh sebesar $49.4 \%$ sisanya $50.6 \%$ dipengaruhi oleh faktor lain.

(Lebu, Wardiah, \& Indasari, 2020) kurang berhasilnya siswa dalam menulis pantun dikarenakan proses pembelajaran pantun untuk siswa belum baik diajarkan oleh guru. Dalam proses belajar pantun guru mengajarkan keseluruhan, guru tidak mengajarkan diksi dan menggunakan pantun yang sudah ada. Dari kondisi belajar pantun yang didapat siswa masih seperti itu siswa masih bingung untuk membuat pantun. Kondisi ini diperlukan bimbingan guru secara baik untuk meningkatkan kemampuan siswa. Peran media diperlukan untuk meningkatkan pemahaman siswa untuk membuat pantun. Penggunaan media diperlukan agar kemampuan dan pengetahuan siswa dapat berkembang dengan baik. (Gumilar, 2014) pemilihan pantun yang digunakan sebagai contoh harus menarik dan dapat memberikan rangsangan kepada siswa sehingga ide-ide yang dimiliki siswa dapat dikeluarkan. Proses pembelajaran menulis pantun memerlukan usaha yang keras dari guru untuk memberikan rangsangan kepada siswa. Pembelajaran yang berkesinambungan diperlukan untuk meningkatkan kemampuan menulis pantun siswa. Kendala yang umum dihadapi siswa ketika menulis pantun adalah ide yang tidak muncul.

(Gafar, 2014) untuk menulis pantun bagi siswa diperlukan penggunaan model pembelajaran dan dukungan dari pihak sekolah dan guru dengan metode pembelajaran yang bervariasi. (Purwanti, 2017) penggunaan model pembelajaran untuk menulis pantun memberikan dampak yang baik bagi kemampuan siswa. Agar hasil kemampuan siswa menulis pantun lebih meningkat diperlukan pelaksaan pelajaran 
menulis sesuai dengan rencana. (Latifah \& Setyaningsih, 2015) menulis pantun dengan menggunakan model pembelajaran baru dapat meningkatkan kemampuan menulis pantun. (Setiawan, 2018) terdapat perbedaan kemampuan menulis pantun antara model konvensional dengan model menulis berantai siswa. Model penulisan berantai lebih efektif dibandingkan dengan model pembelajaran konvensional untuk kemampuan menulis pantun siswa. Pada penulisan pantun diperlukan peran guru untuk memilih model agar siswa lebih tertarik untuk mengikuti kegiatan pembelajaran. (Edy, Suhartono, \& Chamdani, 2016) Penggunaan model pembelajaran yang modern merupakan salah satu inovasi pembelajaran yang bertujuan untuk meningkatkan hasil belajar. Seperti dalam pembelajaran bahasa Indonesia Model Kooperatif Tipe Kancing Gemerincing dapat meningkatkan kemampuan menulis pantun siswa.

(Andhira, 2017) memberikan pendekatanpendekatan pembelajaran memberikan dampak yang positif terhadap kemampuan menulis siswa. Hal yang sama juga diungkapkan oleh (Dafit, 2017) model pembelajaran yang menarik dapat memberikan pengaruh kepada kemampuan menulis siswa.

\section{SIMPULAN}

Dari hasil penelitian dapat diketahui bahwa secara umum motivasi belajar siwa termasuk dalam kategori baik dan kemampuan siswa menulis pantun Bahasa Daerah termasuk dalam kategori Baik. Jika dilihat motivasi belajar terhadap kemampuan menulis pantun Berbahasa Daerah dari hasil penelitian menunjukkan terdapat pengaruh yang sifnifikan artinya terdapat pengaruh motivasi belajar terhadap kemampuan menulis pantun Bahasa Daerah.

\section{SARAN}

1. Untuk meningkatkan motivasi belajar siswa diperlukan modifikasi pembelajaran seperti menggunakan model pembelajaran baru agar siswa lebih tertarik untuk belajar menulis pantun berbahasa daerah.

2. Guru perlu memberikan motivasi eksternal kepada siswa untuk mengembangkan bakat yang dimiliki oleh siswa untuk menulis pantun Berbahasa Daerah.

3. Perlu diberikan sarana dan prasarana kepada siswa untuk kegiatan belajar menulis pantun Bahasa Daerah.

\section{REFERENSI}

Afandi, R. (2015). Pengembangan Media Pembelajaran Permainan Ular Tangga Untuk Meningkatkan Motivasi Belajar Siswa Dan Hasil Belajar Ips Di Sekolah Dasar. JINoP (Jurnal Inovasi Pembelajaran), 1(1), 77-89. Retrieved from

https://ejournal.umm.ac.id/index.php/jinop/ article/view/2450

Afrilia, N., Hamizi, \& Witri, G. (2015). Analisis Kemampuan Menulis Pantun Siswa Kelas V Sd An Namiroh Pusatkecamatan Tampan Kota. JUrnal Online Mahasiswa, 2(2), 1-8. Retrieved from https://jom.unri.ac.id/index.php/JOMFKIP/ article/view/14554

Andhira, R. (2017). Pengaruh Model Kooperatif Tipe Two Stray Terhadap Keterampilan Menulis Karangan Eksposisi Siswa SMP. Geram (Gerakan Aktif Menulis), 5(1), 24 32.

https://doi.org/https://doi.org/10.25299/gera m.2017.vol5(1).409

Angraini, I. S. (2011). Motivasi Belajar Dan Faktor-Faktor Yang Berpengaruh: Sebuah Kajian Pada Interaksi Pembelajaran Mahasiswa. Premiere Educandum, 1(2), 100-109.

https://doi.org/http://doi.org/10.25273/pe.v $1 \mathrm{i} 02.39$

Angraini, V. D., Mukhadis, A., \& Muladi. (2013). Problem Based Learning, Motivasi Belajar, Kemampuan Awal, Dan Hasil Belajar Siswa SMK. Jurnal Ilmu Pendidikan, 19(2), 187-195. Retrieved from

http://journal.um.ac.id/index.php/jip/article/ view/4211 
Dafit, F. (2017). Keefektifan Kemampuan Menulis Kreatif Siswa SD Dengan Model Pembelajaran Multiliterasi. Geram (Gerakan Aktif Menulis), 5(1), 49-57. Retrieved from https://journal.uir.ac.id/index.php/geram/a rticle/view/418

Daud, F. (2012). Pengaruh Kecerdasan Emosional ( EQ ) dan Motivasi Belajar terhadap Hasil Belajar Biologi Siswa SMA 3 Negeri Kota Palopo. Jurnal Pedidikan Dan Pembelajaran, 19(2), 243 255. Retrieved from http://journal.um.ac.id/index.php/pendidik an-dan-pembelajaran/article/view/3475

Edy, S., Suhartono, \& Chamdani, M. (2016). Peningkatan Kemampuan Menulis Pantun Melalui Model Pembelajaran Kooperatif Tipe Kancing Gemerincing Kelas IV SD. Kalam Cendekia PGSD Kebumen, 4(1). Retrieved from https://jurnal.fkip.uns.ac.id/index.php/pgs dsolo/article/download/8752/6675

Emda, A. (2017). Kedudukan Motivasi Belajar Siswa Dalam Pembelajaran. Lantanida Journal, 5(2), 93-196. Retrieved from https://jurnal.ar-

raniry.ac.id/index.php/lantanida/article/vie $\mathrm{w} / 2838 / 2064$

Gafar, A. (2014). Kemampuan Menulis Pantun Dengan Model Pembelajaran Quantum Teaching Pada Siswa Kelas VII . C SMP Negeri 16 Kota Jambi tahun ajaran 2014/2015. Pena, 4(2). Retrieved from https://onlinejournal.unja.ac.id/pena/article/view/2332

Gumilar, D. A. I. (2014). Upaya meningkatkan pembelajaran menulis pantun melalui teknik. Bahtera Bahasa: Antologi Pendidikan Bahasa Dan Sastra Indonesia, 1(1), 1-13. Retrieved from https://ejournal.upi.edu/index.php/PSPBSI /article/view/424

Hidayani, R., \& Arif, S. (2017). Kemampuan Menulis Pantun Oleh Siswa Kelas Vii Smp Swasta Al-Ihsan Medan Tahun Pembelajaran 2016 / 2017. Kode Jurnal Bahasa, 6(3), 1-19. https://doi.org/https://doi.org/10.24114/kjb .v6i3.10826

Indrayeni, S., Hakim, N., \& Burhanudin, D. (2019). Kemampuan Menulis Pantun Siswa Kelas VII SMP Negeri 2 Lirik. Jurnal Tuah Pendidikan Dan Pengajaran Bahasa, 1(1), 69-77. https://doi.org/http://dx.doi.org/10.31258/jt uah.1.1.p.69-77

Irnawati, Kurniati, A., \& Wibowo, D. C. (2017). Hubungan kebiasaan menulis pantun dengan kemampuan berbalas pantun. Jurnal Pendidikan Bahasa, 6(2), 271-280. Retrieved from http://journal.ikippgriptk.ac.id/index.php/ba hasa/article/viewFile/649/606

Latifah, A., \& Setyaningsih, H. (2015). Peningkatan Keterampilan Menulis Pantun Menggunakan Model Pembelajaran Arias Dengan Media Kartu Pantun. Lingua Jurnal Bahasa Dan Sastra, 11(1), 1-12. Retrieved from https://journal.unnes.ac.id/nju/index.php/lin gua/article/view/8920

Lebu, H., Wardiah, D., \& Indasari, M. (2020). Analisis Kemampuan Menulis Pantun Siswa Kelas V. Indonesian Journal of Elementary Education, 2(1), 86-96. https://doi.org/http://dx.doi.org/10.31000/ij oee.v1i2.2934

Marisa, S. (2019). Pengaruh motivasi dalam pembelajaran siswa upaya mengatasi permaslahan belajar. JUnral Taushiah FAIUISU, 9(2), 20-27. Retrieved from https://jurnal.uisu.ac.id/index.php/tsh/articl e/view/1786

Maulina, D. E. (2012). Keanekaragaman Pantun Di Indonesia. Jurnal Ilmiah Program Studi Pendidikan Bahasa Dan Sastra Indonesia Semantik, 1(1), 107-121. Retrieved from http://e-

journal.stkipsiliwangi.ac.id/index.php/sema ntik/article/view/103

Multafifin. (2015). Kemampuan Menulis Pantun Siswa Kelas VII SMP Negeri 52 Konawe Selatan. Junral Humanika, 3(15). Retrieved from http://ojs.uho.ac.id/index.php/HUMANIKA /article/view/587

Murti, F. N. (2017). Jejak Pesona Pantun Di 
Dunia ( Suatu Tinjauan DiakronikKomparatif ) (Sukarman, A. Muti'ah, \& A. Taufiq, eds.). Retrieved from https://jurnal.unej.ac.id/index.php/fkipepro/article/view/4923

Oktiani, I. (2017). Jurnal kependidikan. Jurnal Kependidikan, 5(2), 216-232. https://doi.org/https://doi.org/10.24090/jk. v5i2.1939

Pratiwi, S. M., Hidayat, W., \& Fauzi, M. R. (2020). Analisis kekeliruan menulis teks pantun pada siswa sd kelas v. Collase Creative Onf Leraning Student Elementary Education, 03(05), 237-244. Retrieved from https://journal.ikipsiliwangi.ac.id/index.ph $\mathrm{p} /$ collase/article/view/4564

Purwanti, D. (2017). Dengan Menggunakan Model Berpikir Berbicara Menulis ( Think Talk Write ). Jurnal Diksatrasia, 1(2), 5256. Retrieved from https://jurnal.unigal.ac.id/index.php/diksat rasia/article/view/581

Setiawan, G. K. (2018). Peningkatan Kemampuan Menulis Pantun Dengan Menggunakan Metode Menulis Berantai Studi Eksperimen Pada Siswa Kelas Vii Smpn 1 Kadungora Kabupaten Garut Tahun Pelajaran 2016/2017. Caraka: Jurnal Pendidikan Bahasa Dan Sastra Indonesia Serta Bahasa Daerah, 7(1), 3851. https://doi.org/https://doi.org/10.31980/car aka.v7i1.18

Ulfah, K. R., Santoso, A., \& Utaya, S. (2016). Hubungan motivasi dengan hasil belajar ips. Jurnal Pendidikan: Teori, Penelitian, Dan Pengembangan, 1(8), 1607-1611. https://doi.org/http://dx.doi.org/10.17977/j p.v1i8.6678

Wulansari, D. (2016). Bahasa Pantun Dalam Makna Dan Budaya Masyarakat Me-. Junral Society, VI(2008), 1-13. https://doi.org/https://doi.org/10.33019/so ciety.v4i1.31 